\title{
MODEL FOR ASSESSMENT OF HEALTHCARE INSTITUTIONS' COMPETITIVENESS
}

\author{
Vadim Pashkus, ${ }^{1}$ Natalie Pashkus, ${ }^{2}$ Asya Chemlyakova ${ }^{3}$
}

\begin{abstract}
This article discusses competitiveness of public health institutions, which relates to their market position as ranked by various entities (including government). For this purpose, a model of competitive positioning is designed for assessing healthcare organizations. This model allows one to assess the level of competitiveness of a medical organization, evaluate its market positioning, and develop a strategy for furthering its development using features of their position provided by the model.
\end{abstract}

JEL Classification Numbers: I11, D81, L25; DOI: http://dx.doi.org/10.12955/cbup.v5.950

Keywords: healthcare institutions, strategic positioning, matrix of competitive positioning.

\section{Introduction}

The functioning of a public health policy requires clear priorities for its strategic development. It is necessary to rank healthcare organizations based on their contribution towards goals in the framework of the current economic policy and financial priorities. These priorities include, but are not limited to, improving the health of the nation and providing a high quality of life for the population of Russia (Altunyan \& Kotcofana, 2016). Some institutions are better at coping with the tasks assigned and demonstrate high-performance indicators. Identifying those institutions is important for implementing the healthcare policy (Lyakin, 2015). It is also important to identify those healthcare institutions that are unable to provide the proper level of quality in medical services, including perceived and actual quality (Starobinskaya \& Andrianova, 2010). Monitoring of competitiveness indicators and the ranking of quality should be carried out both in terms of prioritizing financing and the timely implementation of regulatory and anti-crisis measures (Rybakov, Lyakin, \& Cisko, 2013; Plotnikov, Vertakova, \& Polozhentseva, 2015).

Healthcare markets are highly competitive. Institutions compete for consumers and financial resources in the markets of paid services and those related to compulsory health insurance. Healthcare organizations are interested in identifying their market position and determining a promising strategy for reaching leadership. Therefore, it is important to have a tool to determine the competitive status of a healthcare institution in order to rank such institutions for financial assistance in funding medical facilities and projects, and other financial transactions (Lanska \& Hartz, 1998). In using such tools, healthcare organizations could find problem areas in their strategic development and then correct their market strategy.

Assessing the competitive status of a healthcare institution requires linking information about the positioning of a medical organization on the market with the competitive strategy that it implements. Matrix strategic methods are designed to identify structures needed in the positioning of health organizations according to their competitive potential and competitive environment.

This paper describes a model for assessing the competitive positioning of healthcare organizations. This modified model makes it possible to assess and compare the competitiveness of healthcare based on the competitive strategy implemented and the characteristics of the competitive environment of the medical organization. At the same time, assessments should take into account the impact of a number of external positive and negative trends that affect the competitive status of the healthcare organization

The modified methodology allows not only comparison of the competitive positions and competitive strategies but also the development of specific strategic recommendations.

\section{Data and Methodology}

An analysis of the competitive status of public health organizations was constructed based on a modified McKinsey model of strategic positioning (Pashkus \& Pashkus, 2011). It involved an assessment of the strategic potential of health institutions and building an effective strategy to ensure their

\footnotetext{
${ }^{1}$ St. Petersburg State University. v.pashkus@ spbu.ru

${ }^{2}$ Herzen State University. nat.pashkus@gmail.com

${ }^{3}$ Russian State Hydrometeorological University, priemgpa@ mail.ru
} 
competitiveness. The McKinsey methodology works mainly with profitable processes and involves an evaluation of competitive advantages of the product in the context of changes in the appeal of the selected industry. The features of the healthcare market impose a need to modify classical techniques.

The modified McKinsey model for assessing competitiveness under changing environmental factors involves the setting of two integral indicators, which serve as axes for constructing a positioning matrix. Factors of the first indicator, the competitive potential of healthcare institutions, include resource and strategic potential and are plotted along a horizontal axis (X). This integral indicator includes factors that depend on the actions of management in response to changes in another indicator: the competitive environment (Y). The factors of this latter indicator affect the functioning and competitiveness of the healthcare organization and the synergistic effects that can develop under such influence. Estimations of risks are used as correction coefficients to evaluate and select priorities for the competitive strategy of healthcare organization (Kliestik \& Dengov, 2015).

Figure 1 shows the matrix designed for the competitive positioning of healthcare institutions. The entire positioning plane contains nine identical zones. Each competitive position requires separate approaches to the strategy for developing resource potential and implementing various actions aimed at improving both actual and perceived quality of health services. The aim is to prioritize the competitive strategies to develop the resource potential and achieve a competitive position for the healthcare organization by responding to a specific set of conditions about the competitive environment.

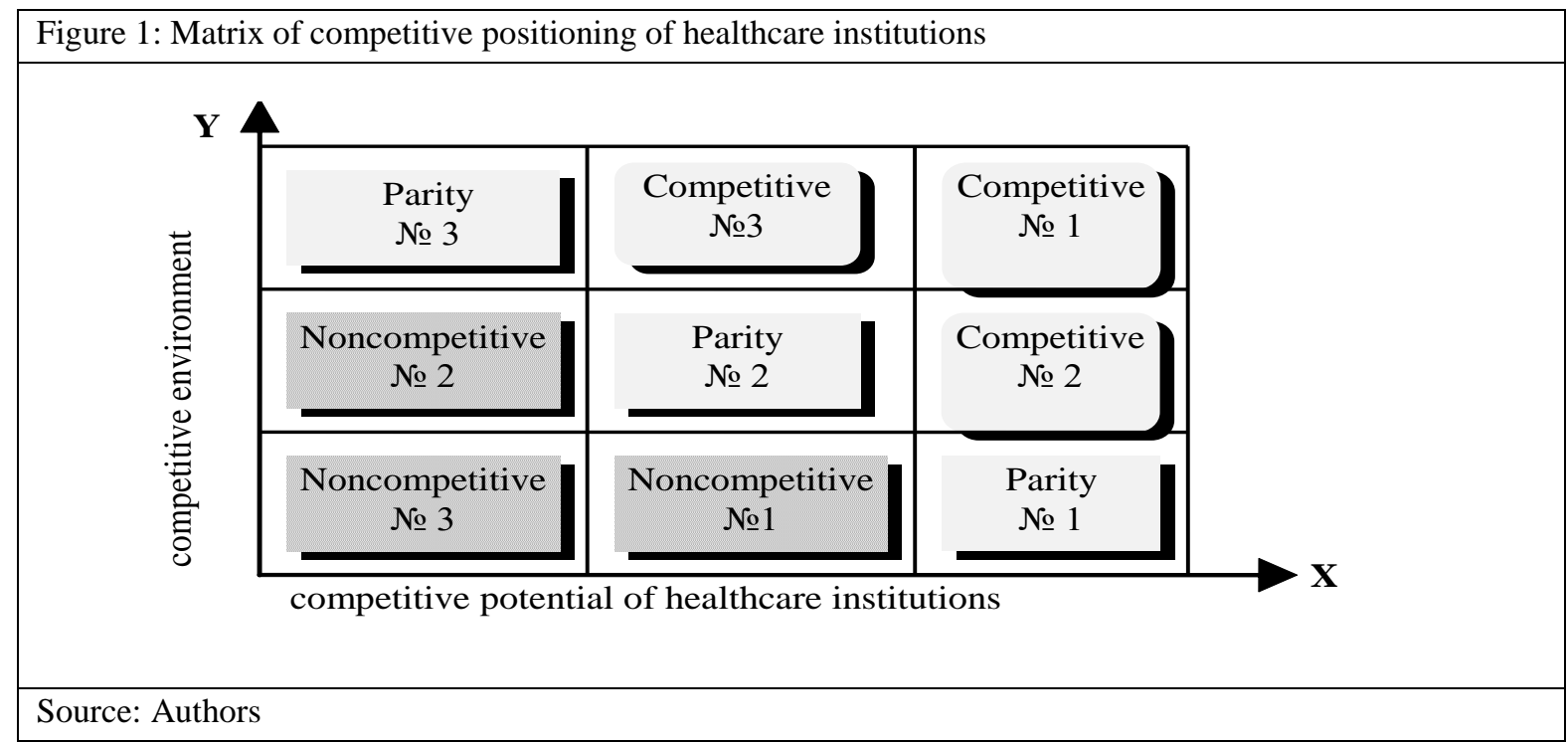

\section{Results and Discussion}

Healthcare organizations placed on the plane of coordinates (X, Y) yield three types of competitive positions according to the model. The first type is competitive, the second parity, and the third noncompetitive. Each has three specific positions. The following provides the characteristics of each competitive position in brief.

Competitive Position One

This position denotes a high potential of competitiveness with a high level of influence for synergetic effects of the competitive environment.

It is a priority area for the strongest and most well-known organizations that can effectively implement innovative, competitive strategies, including breakthrough strategies to promote health services and healthcare organizations as part of their competitive strategies. Medical services of such healthcare organizations are distinguished by high actual and perceived quality. The consumer aspires to select a priority regarding these aspects, both for services included in the list of compulsory health insurance and for paid medical services. At the same time, in such health organizations, as a rule, there are high barriers to accessing medical services under compulsory insurance (Lyakin, 2015). This position presupposes the preservation and strengthening of the competitive status and priorities in the investment from the state and as well as from stakeholders. 


\section{Competitive Position Two}

This position had average attractiveness, average synergetic effects, and high competitive potential. This strategic position is quite strong and stable. At the same time, the healthcare organization is not the leader in terms of competitiveness, but it is relatively promising and attractive. Its medical services have reasonably high levels of actual and perceived quality. The consumer audience is wider than in others. As well, access to medical services under the compulsory health insurance is slightly less complicated (Rybakov, Lyakin, \& Cisko, 2013). As a rule, the development of the resource potential of such a medical institution has been uneven. Therefore, it needs development directed at its resource potential and investment targeted at overcoming weaknesses and consolidating strong points.

\section{Competitive Position Three}

This position in the matrix denotes average competitiveness potential and high levels of external effects. It is somewhat unstable; even slight change in the competitive environment can cause the fall of an organization into a parity zone or even exit into an uncompetitive zone. Position requires a clear identification of the most promising areas for quality resource development (Chesnokova \& Ermakow, 2013). Usually, the services of such organizations do not differ in their actual quality from the average level of the market, but their perceived quality is significantly higher than those of competitors.

\section{Parity Position One}

This position signifies high competitive potential and low influence of synergetic effects of the environment. These institutions, as a rule, have a high 'actual' quality of services. They are characterized by advanced skills in certain areas, but their image potential is not well developed. Such organizations have alternatives. One is to transition to high competitiveness through creating and developing an organizational forte or a forte in selected areas of its activities. This would require implementing activities targeted at improving the resource potential and proper positioning within the healthcare market.

Such a medical organization should focus on optimizing financial and information flows. This would mean the rational use of financial resources from consumers and stakeholders. In particular, it includes carrying out investment targeted at developing priority areas and programs and in the formation of the image. The lack of a developed image prevents the attraction of additional resources.

Another alternative growth strategy in terms of competitive potential is to descend to the uncompetitive zone. This competitive position is unstable. Therefore, in the long term, such organizations will either rise to the competitive zone or lag. It should be noted that underfunding of healthcare organizations in this cluster can lead to an unfavorable alternative trend. This area is most promising for parity organizations due to the high potential of the health organization itself. However, further weakening of image and associated low financing can lead to loss of initiative and, therefore, in the foreseeable future, to further loss of competitiveness. Thus, the state policy of underfunding healthcare organizations within the competitive position will be not only economically inefficient but also unethical concerning the future of the organization, its consumers, and the healthcare system as a whole.

\section{Parity Position Two}

This position denotes average competitiveness potential and the average level of synergetic effects of the environment. It fits the mediocre healthcare organization in all respects with medical services that have average actual or perceived quality. Consumers choose such organizations for their medical services where no other alternative is available. Such medical organizations are highly available, but not all of their current patients are interested in returning to these same healthcare organizations. The health organizations in this competitive zone can only have a highly selective investment in greatly promising and least risky activities. Financial resources are at the minimally acceptable level for state subsidies and are restricted by other stakeholders. Thus, the exit from this position in the direction of increasing competitiveness is limited by its budget. Therefore, the most important direction for developing the resource potential for this organizations is the introduction of new financial instruments aimed at optimizing the internal financial structure. A long duration in this position leads to further decline in the competitive status and decrease in the actual quality of medical services.

Parity Position Three

This one depicts low competitive potential and a high level of synergetic effects of the competitive 
environment. With a low competitive potential, even an extremely high level of positive environmental effect would not ensure an increase in the efficiency of the organization and high level of actual quality of services. Such health organizations, due to the positive influence of competitive environmental factors, experience astounding short-term improvement in their image. However, this increase in attractiveness is not justified by actual actions of the healthcare organization (Chesnokova \& Ermakow, 2013).

The flow of investment associated with image appeal will most likely be inopportunely used by the organization to strengthen its resource potential. Under qualified or unreceptive staff will not be able to carry out the necessary procedures, the purchased equipment will be idle, and cutting edge medical materials will not be used efficiently. Thus, financial resources attracted in the short term are likely to be spent in an unplanned manner and most likely wasted by management. This zone has the most strategically unpromising positions among the other middle zones.

Only effective short-term investments are possible for such healthcare organizations. There is a high probability of abrupt closure of programs and activities. These organizations require tools to control the expenditure of public and stakeholder-provided funds. It is important for such organizations to focus on the organizational, economic, and managerial effectiveness of these processes to form a more open management structure and ensure activation of their resource potential. Therefore, where the healthcare organization can use their latent attractiveness and potentially increase funds by devoting all resources to developing and strengthening the resource capacity, it has a chance of improving their competitive position (Lyakin, 2015). Otherwise, such a healthcare organization will lose its parity position after a certain period, which can be lengthy and possible with a general drop in the quality of medical services and lack of activities on the part of the main competitors.

Nevertheless, actions targeted at developing their resource potential provide a chance for a breakthrough and ensure competitiveness. The organization has the means to act, though there is not always the motivation or ability to effectively use their full potential.

\section{Noncompetitive Position One}

This position displays potential for average competitiveness and synergy of an insignificant but positive competitive environment. These factors are mediocre in terms of competitiveness of the organizations; their image is not fully developed. There may be a generally negative opinion about such a medical institution. The strategy of the organization should be aimed at developing areas with a minimum level of risk and obtaining a feasible (minimum) competitiveness and acceptable quality of services based on their strengths. Changing from this position is difficult since the organization does not have the necessary resources, nor the motivation or ability to implement activities targeted at building the resource potential. It is typical for such organizations to choose a niche strategy where they can achieve some success and strengthen the competitive status through campaigns promoting their image.

\section{Noncompetitive Position Two}

This position entails low competitiveness potential and medium influence of the competitive environment. As a rule, it involves weak organizations with the inadequate level of quality. Their image is not appealing but rather average for the market. These organizations need to concentrate on reducing risks and protecting positions in some of their most promising areas. Changing from this position is even less likely than from the previous one since the potential of the organization is extremely low.

Noncompetitive Position Three

This position depicts low competitiveness potential and low influence of a competitive environment. These are the weakest healthcare organizations; they barely survive. They require practical measures to change position but have difficulty implementing these as an independent.

Overall, to implement the proposed methodology, it was necessary to specify two sets of factors for assessing the specific positions of a healthcare organization according to two indicators: competitive potential and the competitive environment, in which the organizations operate. As noted in Starobinskaya and Andrianova (2010) and Chesnokova and Ermakow (2013), a faulty system of indicators can destroy all advantages of the model. 


\section{Conclusion}

The analysis of competitiveness and the identification of positions in the healthcare market allow an organization to outline the most effective path of further development and determine crucial strategic priorities. An understanding of stakeholder involvement, the development of resource potential, the creation of a positive image, and the brand building of a healthcare organization are all possible following a comprehensive analysis of competitiveness.

\section{References}

Altunyan, A., Kotcofana, T. (2016) Global Political and Economical Processes, Monetary Policy of the Bank of Russia and Development of the Russian Economy. Globalization and its Socio-Economic Consequences. 16th International Scientific Conference Proceedings. University of Zilina, Slovak Republic. Pp. 33-40.

Chesnokova, M.S., Ermakow, Y.V. (2013) Strategic Marketing. St. Petersburg: KultInform Press.

Gregova, E., Dengov, V. (2015) The Practical Economic Policy in Transition Economies of V4 Countries at the Present Stage of Globalization. Globalization and Its Socio-Economic Consequences, Pts I and II. 15th International Scientific Conference Proceedings. University of Zilina, Slovak Republic. Pp. 150-156.

Kliestik, T., Dengov, V. (2015) Quantitative Approach to Risk as a Social Phenomenon. 2015 5th International Conference on Applied Social Science. Vol. 80. Pp. 28-33.

Lanska, D.J., Hartz, A.J. (1998) Measurement of quality in healthcare. Neurology. Vol. 50. Iss. 3. Pp. 584-587.

Lyakin, A.N. (Ed.) (2015) Economic policy. Moscow: Yurayt.

Pashkus, V.Y., Pashkus, N.A. (2011) Algorithmization of a Strategic Analysis Matrix Instruments and Approaches to Their Application in a Noncommercial Sector of Economy. Strategic management. Iss. 3. Pp. 200-218.

Plotnikov V., Vertakova Yu., Polozhentseva Yu. (2015) of Detecting Imbalances in the Structure and Dynamics of SocioEconomic System. SGEM 2015. International Multidisciplinary Scientific Conference on Social Sciences and Arts Political Sciences, Law, Finance, Economics and Tourism Conference Proceedings. Pp. 821-828.

Rybakov, F.F., Lyakin, A.N., Cisko, S. (Ed.) (2013) Globalization and development of infrastructure. Zilina: University of Zilina.

Starobinskaya, N. M., Andrianova, N. V. (2010) Market research: Textbook. St. Pitersburg: Herzen University Publisher. 